\title{
Polyvariation of the development Scutellaria L. species and the structure of their populations in Siberia
}

\author{
Alexandra Guseva*, and Vera Cheryomushkina \\ Central Siberian Botanical Garden SB RAS, 630090 Novosibirsk, Russia
}

\begin{abstract}
Structure of coenopopulations and polyvariance of the development of species of the genus Scutellaria in Siberia were described. Species of the genus are semi-wood and grassy life forms. The formation of different life forms is confined to specific habitats. In a number of species (S. galericulata, S. grandiflora и S. supina), the life form is changing. Dimensional polyvariance of individuals of $S$. scordiifolia in different habitats was found. The ontogenetic structure of coenopopulations is diverse; 3 types of spectrum are formed: left-sided, centered, and right-hand. In individuals of S. supina and S. tuvensis, the duration of ontogenesis and the duration of individual ontogenetic conditions are influenced by living conditions. The polyvariance of selfmaintenance was revealed in S. supina, the transition from completely seed self-maintenance to mixed - seed reproduction in combination with vegetative. The spatial structure and density of coenopopulations vary depending on the habitat conditions. The spatial structure of the studied species is also determined by the peculiarities of self-maintenance of coenopopulations. The change in density is also associated with the mobility of the substrate on steep, rocky mountain slopes in vegetatively stationary species and with projective cover in vegetatively mobile ones.
\end{abstract}

\section{Introduction}

Each species in the plant community is represented by a coenopopulation. Cenopopulation has its own structure and consists of individuals differing in absolute age, ontogenetic state and other characteristics [1]. The study of various aspects of the structure of coenopopulation makes it possible to identify adaptation mechanisms that ensure their sustainable position in plant communities [2,3].

Species of the genus Scutellaria L. growing in Siberia are objects of study. For this territory, 13 species are indicated [4], they grow in a wide range of habitats: from marshy and wet meadows on the plain to stony slopes and rocks in the highlands.

\section{Results and discussion}

\footnotetext{
*Corresponding author: guseva.sc@list.ru
} 
Resilience of coenopopulations of species of the genus Scutellaria in different coenoses of Siberia is ensured by population adaptations. Adaptations are manifested in a variety of life forms, changes in the dimensional characteristics of individuals, parameters of ontogenetic structure, density, type of spatial structure, pace of development and methods of selfmaintenance.

Life forms. Species of the genus are semi-wood and grassy life forms. The genus is dominated by polycarpic terrestrial herbs [5]. Herbal biomorphs are formed mainly in species growing in swamps, meadows and steppes. In species that are common in the desert steppes and on the rocks, as a reflection of adaptation to more arid habitats, subshrub dwarf subshrub and dwarf subshrub life forms are formed. Three species in different ecologicalphytocenotic conditions revealed morphological polyvariance, two or more life forms are formed [6]. Species of S. galericulata form 2 grassy life forms; S. grandiflora - herbaceous (taproot herbaceous polycarpic) and semi-woody (dwarf subshrub); in individuals of S. supina, 4 life forms are formed: semi-woody (dwarf subshrub and subshrub dwarf subshrub) and herbals (taproot herbaceous polycarpic and longrhizomatous-taproot herbaceous polycarpic).

Dimensional polyvariance. In different habitats, individuals differ in size. Thus, dimensional polyvariance was found in individuals of $S$. scordiifolia in different habitats: stepp meadow - bunchgrass stepp - meadow stepp. Analysis of average indicators of signs showed that in most of the signs, the largest are individuals growing on a stepp meadow. By most indicators, individuals of bunchgrass steppes and meadow steppes, as well as stepp meadows and meadow steppes, differ from each other. The stolone-forming life form is formed in individuals of $S$. scordiifolia, the species also belongs to vegetative annuals, it is mainly characterized by vegetative reproduction. Such morphometric indicators as the number of stolons of $n+1$ order and their length give an idea of the prospects for the development of this species in specific living conditions. These parameters show its ability to consolidate and develop new territories. S. scordiifolia. Based on the data obtained, the most favorable living conditions for individuals of $S$. scordiifolia are steppe meadows with a high projective cover.

Types of self-sustaining. One of the main indicators of the state of coenopopulation is its ability to sustain self-maintenance. In most species of the dwarf subshrub life form, selfmaintenance occurs only by seed. Grassy biomorphs in most cases have a mixed type of self-maintenance. In individuals of S. supina in different habitat conditions, a change in the type of self-maintenance occurs. Self-maintenance of coenopopulations is carried out only by seed in bunchgrass and meadow steppes. Long root shoot [7] appear in the conditions of steppe meadows, self-maintenance type mixed: seed renewal in combination with vegetative [8].

The pace of development. The polyvariance of the rates of individuals' development ensures the heterogeneity of individuals in coenopopulations, thereby increasing their stability in different ecological-phytocenotic conditions. The effect of habitat conditions on the duration of the ontogeny of individuals and the duration of individual ontogenetic conditions was found in S. supina and S. tuvensis. In S. supina, the temporal polyvariance is described in individuals of different life forms and in one life form under different ecological-phytocoenotic conditions. The longest life expectancy (50-55 years) was observed in the subshrub dwarf subshrub life form, the smallest life expectancy was found in taproot and longrhizomatous-taproot forms (from 21 to 30 years). In individuals of taproot life forms in different habitats, differences in the duration of the middle-aged and old generative states are observed. In $S$. tuvensis, 4 classes of polyvariance are described: normal development; slow development; accelerated development; missing one or more developmental states [9]. 
Ontogenetic structure of coenopopulations. Ontogenetic structure reflects age-related heterogeneity of coenopopulations. In general, this indicator is quite dynamic, but the study of changes in the ontogenetic structure makes it possible to identify the characteristics of the adaptation of species to the conditions of existence. Ontogenetic structure of coenopopulations of Siberian species of different life forms differs in diversity, 3 types of spectrum are formed: left-sided, centered and right-sided. In some species, the formation of several types of spectrum is noted. Thus, in S. tuvensis, the formation of three types of spectrum is associated with a change in the rates of development of individuals in different ecological-coenotic conditions. In individuals of $S$. supina, the formation of several types of spectrum is determined by the change of life form and the method of self-maintenance in different habitat conditions. The variety of types of spectrum, characteristic of individual species, indicates their high ability to adapt to environmental conditions.

The spatial structure of the elementary demographic units (EDU) and the density of individuals. EDU is many individuals of the same species, necessary and sufficient to ensure the sustainable turnover of generations in the smallest possible territory [10]. The change in the spatial structure of the ede and density in different habitats ensures the stability of coenopopulations of the species. Thus, depending on the habitat conditions, the spatial structure and density of the coenopopulations of $S$. grandiflora, S. tuvensis, $S$. galericulata and $S$. ikonnikovii changes. Two types of EDU spatial structure are described: discontinuous and continuous.

The continuous type of spatial structure in the vegetatively stationary species of $S$. grandiflora and $S$. tuvensis is formed on stony, gravelly slopes, pebbles and coarse scree; in narrow gorges - discontinuous type of spatial structure. The continuous type of spatial structure in the vegetatively stationary species of $S$. grandiflora and $S$. tuvensis is formed on stony, gravelly slopes, pebbles and coarse scree. The change in density (2.5-20.5 individuals per $\mathrm{m} 2$ ) is associated with the mobility of the substrate on the steep stony slopes of the mountains, and, as a result, the preservation of individual species only near large stones or on a substrate fixed by other species. A continuous type of spatial structure is formed in the meadows of vegetatively mobile species with irregular seed propagation of S. ikonnikovii and S. galericulata. On the rocky river banks - discontinuous type of spatial structure. Eremas as a result of irregular seed breeding fall into the water, which contributes to their spread along the river bank. Individual EDU of different ages are mainly concentrated around large trees. Since the species is vegetatively mobile, EDU of different ages in the population are represented by clones. The ecological density of individuals in EDU depends on the total projective cover: the higher it is, the more intense the disintegration processes and the greater the density of individuals.

Thus, the adaptation of species of the genus Scutellaria to ecological-phytocoenotic conditions occurs in different ways. The variety of adaptations allows the species to adapt to the constantly changing environmental conditions and to occupy a stable position in various plant communities.

The work was carried out with the financial support of the grant of RFBR within the framework of scientific project № 18-04-00621-a and project of the State Assignment of Central Siberian Botanical Garden of the Siberian Branch of the Russian Academy of Sciences № AAAA-A17-117012610053-9.

\section{References}

1. O.V. Smirnova, L. B. Zaugol'nova and etc, Cenopopulation of plants (Nauka, Moscow, 1976)

2. L.B. Zaugol'nova, L. A. Zhukova and etc, Plant cenopopulations (population biology essays) (Nauka, Moscow, 1988) 
3. L.A. Zhukova, Population life of meadow plants (Yoshkar-Ola, 1995).

4. V.V. Zuev, Flora of Siberia. Pyrolaceae-Lamiaceae (Labiatae), 11 (Novosibirsk, 1997)

5. V.A. Cheryomushkina, A. A. Guseva, Life forms of the species of the genus Scutellaria L. (section Lupulinaria A. Hamilt) in North and Central Asia (Baku, 2016)

6. A.A. Guseva, V. A. Cheryomushkina, Classification of life forms of species of the genus Scutellaria L. (Lamiaceae) (Vladivostok, 2017)

7. L.Ye. Gatcuk, Bull. MOIP, 79(1) (1974)

8. V.A. Cheryomushkina, A.A. Guseva, Contemporary Problems of Ecology, 8(5) (2015)

9. A.A. Guseva, V. A. Cheryomushkina, Bull. MOIP, 122 (2017)

10. O.V. Smirnova, L.B. Zaugol'nova, R.V. Popadyuk, Biology Bulletin Reviews, 54(3) (1993) 